УДК 616.728 .3

DOI: 10.18101/2306-1995-2019-3-15-19

\title{
ЛЕЧЕНИЕ ОСТЕОАРТРОЗОВ КРУПНЫХ СУСТАВОВ МЕТОДОМ ИГЛОНОЖА
}

\author{
(C) Шигаев Евгений Станиславович \\ кандидат медицинских наук, \\ заведующий отделением травматологии и ортопедии \\ Республиканская клиническая больница имени Н. А. Семашко
}

главный внештатный травматолог-ортопед,

Министерство здравоохранения Республики Бурятия

Россия, 670023, Улан-Удэ, ул. Павлова, 12

E-mail: shigaev72@mail.ru

В статье дается определение термину «иглонож», описывается история возникновения и развития акупотомологии в КНР, дается описание технологии лечения автором остеоартроза тазобедренных и коленных суставов иглоножом с ближайшими результатами.

Ключевые слова: остеоартроз; иглонож; боль; функция; акупотомология; иглорефлексотерапия.

Для цитирования

Шигаев Е. С. Лечение остеоартрозов крупных суставов методом иглоножа // Вестник Бурятского государственного университета. Медицина и фармация. 2019. Вып. 3. С. 15-19.

\section{История развития акупотомологии}

В 1976 г. доктор Чжу Ханьчжан (провинция Цзянсу, КНР), работая в поселковой больнице, успешно излечил больные мышцы руки одного из своих пациентов, заменив при этом медицинский скальпель на инъекционную иглу девятого размера. Таким образом было положено начало практики лечения иглоножом.

После аттестации, проведенной в 1984 г. управлением здравоохранения провинции Цзянсу, в 1985 г. данная практика была рекомендована к распространению по всей стране.

В 1993 г. было создано отделение по иглоножу при Китайской ассоциации китайской традиционной медицины. В последующие 10 лет в Австралии, Южной Корее, Малайзии и других 15 странах и регионах одно за другим были созданы медицинские сообщества по иглоножу. В более чем 40 странах и регионах были созданы лечебно-диагностические учреждения по данной методике лечения.

В сентябре 2003 г. решением экспертной комиссии, организованной при Государственном управлении по делам традиционной медицины, методика лечения иглоножом стала официально именоваться акупотомологией, а также определена в качестве отрасли медицины.

По статистике отделения иглоножа при Китайской ассоциации традиционной медицины, в настоящее время уже более ста тысяч медицинских работников по всему Китаю занимаются методикой лечения иглоножом, ежедневно по всей стране свыше пятисот тысяч пациентов получают подобное лечение. За предела- 
ми КНР более трех тысяч обученных врачей применяют иглонож при лечении самых различных заболеваний.

В акупотомологии сочетаются абстрактное мышление восточной культуры и образное мышление западной культуры. Бывший председатель Всемирной федерации научных обществ по иглорефлексотерапии профессор Ван Сюэтай отметил: «Китайская медицина выходит на мировую арену, и самые высокие перспективы у иглоножа» [1].

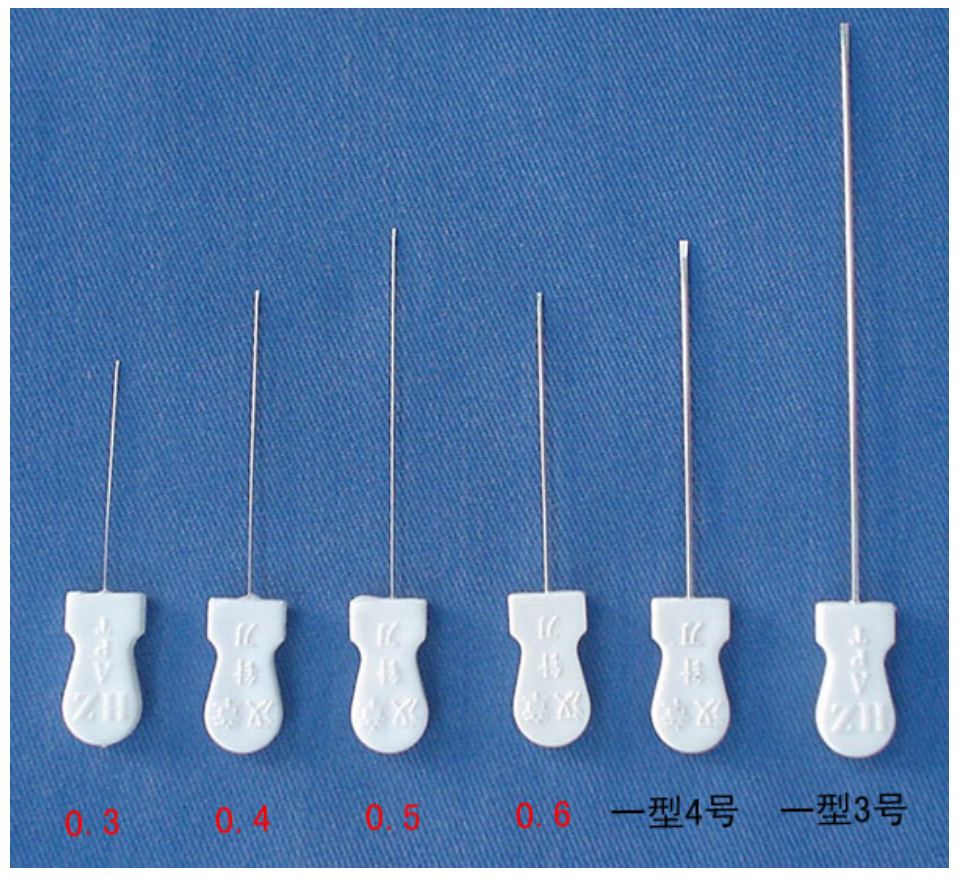

Так что же такое иглонож? Фактически это специальная игла, на конце которой имеется режущее плоское острие. Перевод с китайского звучит следующим образом: «Инструмент, с помощью которого осуществляются резательные и другие функции путём введения иглы в определённые места человеческого тела, называется иглоножом».

По данным китайских авторов, значительные результаты достигнуты в лечении следующих заболеваний:

- поясничные боли, все виды межпозвоночных грыж, спондилолистез, хондроз, остеохондроз всех отделов позвоночника;

- патология суставов - артриты, артрозы, остеопороз, ревматическая болезнь, коксартроз;

- растяжения связочного аппарата, патологические состояния менисков;

- диабет, бронхиальная астма, болезни сердца, аллергические заболевания, почечные патологии, простатит;

- трудноизлечимые пяточные шпоры;

- реабилитация после костных переломов различной тяжести.

По данным китайской медицинской статистики, в 96\% случаев происходит полное выздоровление пациентов. Абсолютными противопоказаниями для лече- 
ния иглоножом являются онкологические процессы и тяжелые инфекционные состояния.

Цель исследования: оценка результатов лечения остеоартрозов крупных суставов технологией иглоножа (асupotomy).

\section{Материалы и методы}

Автор прошел обучение на международном семинаре «Практическое использование метода «"Три иглы" при различных заболеваниях» (удостоверение о повышении квалификации 180000745590), очное обучение (лицензия № 540102004212) в декабре 2016 г. и декабре 2017 г. в Сычуаньской ортопедической клинике Аосыди под руководством проф. Лай Чжигана и проф. Чэнь Гуаньфу.

В период с 1 января 2017 г. по 1 апреля 2018 г. автором наблюдались 36 пациентов с гонартрозами 2-3-й степени и 29 пациентов с коксартрозами 2-3-й степени (в том числе 12 пациентов с асептическим некрозом головок бедренных костей) в возрасте от 26 до 74 лет, 39 женщин, 26 мужчин. Степень остеоартрозов подтверждалась результатами МРТ и рентгенографии суставов. Лечение носило амбулаторный характер.

Оценка функциональных расстройств и болевого синдрома до и после процесса лечения проводилась для тазобедренных суставов по шкале Харриса, для коленных суставов по визуальной аналоговой шкале (ВАШ).

\section{Результаты и обсуждение}

Лечение остеоартроза тазобедренного сустава проводилось по рекомендованной специалистами клиники Аосыди схеме: в асептических условиях точечное рассечение фасции, мышц и капсулы сустава из пяти стандартных точек в надвертельной и вертельной области бедра, этап лечения складывался из четырех еженедельных сеансов и пяти последующих ежемесячных сеансов с оценкой по шкале Харриса по завершении этапа лечения.

Лечение гонартроза 2-3-й степени также проводилось по рекомендованной схеме: в асептических условиях точечное рассечение фасции, сухожилия четырехглавой мышцы, собственной связки надколенника и капсулы сустава из пяти стандартных точек однократно или в случае сохранения болевого синдрома повторные процедуры еженедельно не более трех недель с оценкой результатов лечения по ВАШ.

В течение первых двух суток пациентам не рекомендовалась физическая активность во избежание воспалительных осложнений, и в случае возникновения выраженного болевого синдрома назначался препарат Аркоксиа (60, 90 или 120 мг в зависимости от интенсивности боли). При возникновении субъективного ощущения «нестабильности» в суставе в некоторых случаях назначалась ходьба с помощью трости или костылей до нормализации состояния. 24 (66,6\%) пациентам с гонартрозом, а также пациентам с активной социальной функцией после процедуры иглоножа накладывался кинезиотейп на коленный сустав для стимуляции местного кровоснабжения и уменьшения возможного отека. Следует отметить, что ни в одном случае не было генерализованной гипертермии, инфекционных или неврологических осложнений. 
При оценке пациентов с заболеваниями тазобедренных суставов средний балл по шкале Харриса составлял 41, после курса лечения методом иглоножа средний балл равнялся 75, среднее улучшение произошло на 34 балла, что расценивается как значительное улучшение состояния больного (максимальное количество баллов по шкале Харриса - 100). При этом у пяти пациентов $(17,2 \%)$ с коксартрозом 2-й степени констатировано полное отсутствие боли, даже при ходьбе на большие расстояния и занятиях спортом.

Оценка результатов лечения иглоножом пациентов с гонартрозом проводилась по визуально-аналоговой шкале (от 0 до 10), в которую была включена не только оценка выраженности болевого синдрома, но и субъективное улучшение функции коленного сустава. До лечения средний балл по ВАШ был равен 4,1, после процедур иглоножа оценка пациентом была 8,3 (среднее улучшение на 4,2 балла), у семи пациентов $(19,4 \%)$ удалось полностью купировать болевой синдром.

Важно отметить, что из 65 пациентов у 42 (64,6\%) были проблемы с поясничным отделом позвоночника (грыжи дисков), подтвержденные результатами MPT, и выраженные изменения нижних конечностей по результатам электронейромиографии нижних конечностей (ЭНМГ). Остальные пациенты МРТ и ЭНМГ до процесса лечения не проходили. В настоящее время нами проводятся исследования по объективизации и статистической обработке данных, позволяющие дифференцировать первичные и вторичные заболевания суставов.

\section{Выводы}

Таким образом, медицинская технология иглоножа улучшает состояние больных с заболеваниями крупных суставов, повышает их функцию и уменьшает болевой синдром, что позволяет пациентам не только социально адаптироваться, но и избежать дорогостоящих и травматичных методов оперативного лечения. Способ и техника проведения подобных манипуляций требуют абсолютного знания врачом профильной анатомии, подготовки специалистов в условиях медицинских центров, не только имеющих теоретическую и практическую базу, но и значительный опыт в акупотомологии.

\section{Лuтература}

1. 实用针刀术 / 陈关富, 赖志刚 Shiyong zhendaoshu / Chen Guanfu, Lai Zhigang (Практический иглонож / Чэнь Гуаньфу, Лай Чжиган. Ченду: Сычуаньское научнотехническое издательство, 2004. Изд. 2. 156 с. 


\section{TREATMENT OF LARGE JOINT OSTEOARTHROSES}

BY ACUPOTOMY METHOD

\section{Evgeny S. Shigaev}

Candidate of Medical Sciences, Manager of Unit of Traumatology and

Orthopedics State Autonomous Healthcare Institution

Republican Hospital of N.A. Semashko, Ulan-Ude,

Chief Non-Staff Traumatologist-Orthopedist

Ministry of Healthcare of the Republic of Buryatia, Ulan-Ude

E-mail: shigaev72@mail.ru

The article gives the definition to the term "iglonozh" (acupotomy), the history of emergence and development of akupotomologiya in the People's Republic of China is described, the description of technology of treatment by the author of an osteoarthrosis of hip and knee joints with "iglonozh" with the immediate results is given.

Keywords: osteoarthrosis, acupotomy, pain, function. 